\title{
Implementing a Preventive Maintenance Planning Model for Computer Numerical Control (CNC) Milling Machine
}

\author{
Muhammad Salman Sarfraz \\ Department of Mechanical Engineering, University of Engineering and Technology, Lahore, Pakistan \\ Email address: \\ msalmansarfraz@gmail.com,2014me20@student.uet.edu.pk \\ To cite this article: \\ Muhammad Salman Sarfraz. Implementing a Preventive Maintenance Planning Model for Computer Numerical Control (CNC) Milling \\ Machine. American Journal of Embedded Systems and Applications. Vol. 5, No. 6, 2017, pp. 44-47. doi: 10.11648/j.ajesa.20170506.11
}

Received: October 4, 2017; Accepted: November 20, 2017; Published: January 2, 2018

\begin{abstract}
Preventive maintenance is early access or pre-planned maintenance of the problems occur in any machinery units and it has become the important part of today's industry to avoid breakdown as it can save costly faults, keep Continues production with standardize machinery, reduce waste and also important for safety of deployment. The paper describes the way to avoid breakdown in CNC's by using time based scheduled preventive maintenance for different parameters, while taking 20 CNC machines under observation. PM sheet of CNC's is divided into parts over time for different parameters like chuck pressure inspection is kept in daily basis list while ATC Arm in 4 month check list. Some parameters set on the basis of theoretical studies of material fatigue life and some on experimental basis in the resultant sheet. The developed sheet could help manufacturers to figure out the problems in CNC's on their usage over time range, simply the sheet can be taken as survey of performance of CNC's. Also a proper planed PM sheet can save a valuable amount of money on maintenance.
\end{abstract}

Keywords: PM: Preventive Maintenance, CNC: Computer Numeric Control, BM: Breakdown Maintenance,

CNC: Milling M/c, CNC: Machine Tools, Machining Materials

\section{Introduction}

Maintenance is a most important activity in production process since it accounts about 60 to $75 \%$ of its total costs; including material, transport and technical support costs. As the cost of maintenance is extremely high, industrial studies have revealed that the amount of replacing worn components may be up to $70 \%$ of the total maintenance cost [1] [2]. So, a proper scheduled preventive maintenance modal can be solution for increasing components life, decreasing cost factor also sudden breakdown in machines, which directly disturbs production process more specifically, loss of time and cost for technical work. Another important factor is control of quality, which directly depends upon the condition of equipment. To maintain the standard of product, performance of equipment can only be preserved by its preventive maintenance [3].

The research is focused on problems arising in CNC machines after scheduled preventive maintenance for different parts of CNC's. The main objective was to develop a Time based PM sheet that overcome all the possible issues of maintenance. Although mathematically analysis are best describe by Marseguerra M, Zio E, Podofillini L. [4] Mazzuchi TA, Soyer R. [5].

PM sheet divided into daily, 5 day, 2, 4 and 8 month basis by taking single shift into account for a day which can may be adjusted for multiple shifts on the basis of time. Check sheet includes the following points Check Point Details, Standard, Check Method/ Method of Maintenance, Condition/Reading and Remarks.

Standard defines for which parameter you need to check although some standards used in following sheets may vary because it completely depends on types of application like hydraulic pressure used here is $4 \mathrm{Mpa}$ which can be different for any other application, while check method is basic inception method used for each check point. At the end you can may write for the condition and remarks for further improve the point you checking for. Method of maintenance for each check point been defined as per used for the following research.

\section{Preventive Maintenance}

Preventive maintenance is early access or pre-planned 
maintenance of the problems occur in any machinery units and it has become the important part of today's industry to avoid breakdown as it can save costly faults, keep Continues production with standardize machinery, reduce waste and also important for safety of deployment. This maintenance includes adjustments, alignment, cleaning, lubrication, Oil changing, repairs, replacements, and the extension of equipment life [6] [7] [8]. These activities if not controlled increase the rate of occurrence of Breakdowns and also reduces effective age of equipment. Although Preventive maintenance can be categorized into two parts as unit repairing or unit replacement. If these activities controlled properly, it can minimize cost for replacement of tools by effectively increasing its life also controls the quality of production by the equipment.

U. S. Department of Energy estimates that preventive maintenance can be result in, if implemented properly [9];

1. Up to a $30 \%$ reduction in energy and maintenance costs

2. $35 \%$ to $45 \%$ fewer breakdowns

3. Reductions in downtime by up to $75 \%$.

Preventive Maintenance Check Sheet Standards

Preventive maintenance sheet prepared include check points on following time periods,

1. Daily Check Points

2. 5 day Check Points

3. 2 months Check Points (single shift per day)

4. 4 months Check points (single shift per day)

5. 8 months Check points (single shift per day)

A complete Sheet is a prepared plan followed by monthly and daily schedules.

Check Sheets of specific type Machine units are prepared, which includes all the factors that should be maintained to avoid occurrence of any kind of Breakdown in equipment.

\section{Checklists}

Check lists are of great importance for preventive maintenance as it overcomes all weak memory points including in it. The checklists regarding CNC's in any production line has its importance in $\mathrm{PM}$ as failure in any point can cause drop in production of specimens on machinery. Therefore a proper PM sheet should be implemented in any industry regarding this issue.

As in Atlas Honda Sheikhupura, Pakistan CNC check sheets were made on the time schedule of 3 months and 2 shifts a day industry runs. So, these 3 month based check sheets were not sufficient to avoid Break down in CNC's. It has become big problem in industry as they having breakdowns in some check points after PM.

\section{Cause of Breakdown}

Breakdowns maintenance is maintenance, which performed on worn-out or unusable equipment. [10] [11] Breakdowns in machinery always costly. The major cause for the breakdowns in any part are because of improper modal of PM sheets also it can also be due to improper operation. Although, improper operation problems are easy to overcome, they only need proper training of operator.

\section{Solution of Breakdown}

Multiple breakdowns in machinery can be catastrophic and can be reason for mass destruction of unit and big loss of amount. Therefore breakdowns must be addressed properly with proper planning sheets. My check sheet totally based on time as base parameter for PM to avoid Breakdowns for different checkpoints although time chosen for maintenance is different for different parts of CNC's. As fatigue and failures in any working unit are based on the time so their maintenance should be time based. So, this check sheet named as Time-Based Check Sheet for Preventive Maintenance.

\section{Collection of Data and Methodology}

All the data collected from the previously recorded check sheets of breakdowns in CNC's. I checked for the breakdowns most occurring in CNC's over the period of time they occurs. After successful data collection, I analysed all breakdowns of previous five year which lend me to develop this sheet over problems occurring on time based e. g. the chuck pressure causing issues is in daily inspection checklist previously it was in monthly check sheet. The results been concluded on the basis of implementation of sheet for three completed schedule periods for $20 \mathrm{CNC}$ milling machines.

During implantation process it's been decided that daily check points will be covered by operator, while other check points will be inspected by maintenance department.

\section{Preventive Maintenance Improved Sheet for CNC}

Table 1. Preventive Maintenance Check Sheet for CNC Milling machine.

\begin{tabular}{lll}
\hline Check Sheet for PM of CNC Milling Machine & \\
\hline Check Point Details & Standard & $\begin{array}{l}\text { Check Method/Method } \\
\text { of Maintenance }\end{array}$ \\
\hline Daily Check Points & & Condition/Reading \\
Hydraulic pump Pressure & 4Mpa & Gauge \\
Hydraulic Fluids & Right Operating level & Gauge \\
Chuck Pressure/tool stopper bar & Right Operating level & Gauge \\
Check for Pipe leakage \& connections & No leakage & Gauge \\
\hline
\end{tabular}




\begin{tabular}{|c|c|c|c|c|}
\hline \multicolumn{5}{|l|}{ Check Sheet for PM of CNC Milling Machine } \\
\hline Check Point Details & Standard & $\begin{array}{l}\text { Check Method/Method } \\
\text { of Maintenance }\end{array}$ & Condition/Reading & Remar-ks \\
\hline Lube level & Right Operating level & Gauge & & \\
\hline Grease any part if needed & Minimize friction & By Hand & & \\
\hline Chips & Pan should be clean & By Hand & & \\
\hline Glass of door & should be Clean & By Hand & & \\
\hline \multicolumn{5}{|l|}{5 day Check Points } \\
\hline Filter of Control Cabinet & Clean for air flow & By High air pressure & & \\
\hline \multicolumn{5}{|l|}{2 months Check Points (single shift per day) } \\
\hline Grease chains of Conveyers & Minimize friction & By Hand & & \\
\hline Mist Collector & should be Clean \& properly working & Visual/By hand & & \\
\hline Filters of Coolant tank & should be Clean & Visual/By hand & & \\
\hline \multicolumn{5}{|l|}{4 months Check points (single shift per day) } \\
\hline Spindle run out & At Nose $08 \mu \mathrm{m}$ & Dial Gauge & & \\
\hline Spindle Rotation & Check rotation & Visually & & \\
\hline Spindle taper flange Condition & Visual Check & Visually & & \\
\hline Spindle Orientation & Orientation Position & Visually & & \\
\hline Spindle Clamp force & $2.3 \mathrm{KgN}$ & Pull meter & & \\
\hline Unclamp Stroke & $0.5-0.7 \mathrm{~mm}$ & Pull meter & & \\
\hline Spindle Vibration, Noise \& Temp. check & $20 \mathrm{C}$ & Thermometer & & \\
\hline Balance of CNC & Fix if needed & Bubble level & & \\
\hline ATC Arm & Check external watching & Visually & & \\
\hline Radiator Fins & Clean and straight & Visually & & \\
\hline Emergency Push Button & Machine should be OFF & Check By Hand & & \\
\hline Check earth Leakage Breaker & Check Connections & Check By Hand & & \\
\hline Take off Chuck and Jaws & Clean them & By Hand & & \\
\hline Hydraulic Oil Replacement & drain tank \& replace & By Hand & & \\
\hline Check Wipers & Clean and Undamaged & By Hand & & \\
\hline Line Filter & Change & By Hand & & \\
\hline Suction Filter & Change & By Hand & & \\
\hline Lubricant & drain tank \& replace & By Hand & & \\
\hline \multicolumn{5}{|l|}{8 months Check points (single shift per day) } \\
\hline Cam Box & $\begin{array}{l}\text { Backlash check for Horizontal and } \\
\text { vertical direction of Arm Axis }\end{array}$ & Visualize/By Hand & & \\
\hline Headstock \& tailstock & Clean \& taper check & By Hand & & \\
\hline Spindle & $\begin{array}{l}\text { Check Radial \& End Play } \\
\text { misalignments }\end{array}$ & Dial Gauge & & \\
\hline Chuck Cylinder & Run out & & & \\
\hline Z-axis motor brake & No down after Emergency & By Hand & & \\
\hline Backlash & $\mathrm{X}, \mathrm{Y} \& \mathrm{Z}$ Axis & Dial Gauge & & \\
\hline $\begin{array}{l}\text { Noise (Rapid Motion) Ball screw \& LM } \\
\text { guide }\end{array}$ & $\mathrm{X}, \mathrm{Y} \& \mathrm{Z}$ Axis & Hearing & & \\
\hline $\begin{array}{l}\text { Visual Check (Nut case, LM guide its seat \& } \\
\text { lead Ball screw) }\end{array}$ & $X, Y \& Z$ Axis & Visually & & \\
\hline$X \& Z$ axis Gibs & Adjust if needed & Dial Gauge & & \\
\hline Noise Check for support bearing & $\mathrm{X}$-axis & Dial Gauge & & \\
\hline Tool Stopper bar & Loosening state of wear out & Visual/By hand & & \\
\hline Key & Loosening state of wear out & Visual/By hand & & \\
\hline Gripper for tool exchange & Loosening state of wear out & Visual/By hand & & \\
\hline Roller Stopper & Loosening state of wear out & Visual/By hand & & \\
\hline Magazine ZRN Position & Check Index Position & Visual/By hand & & \\
\hline Tool Magazine Ports & Properly Working & Visual/By hand & & \\
\hline Filter Replacement & check and replace & Visual/By hand & & \\
\hline Lubrication Blockage & shouldn't block & Visual/By hand & & \\
\hline Change Hydraulic Oil & check and replace & Visual/By hand & & \\
\hline Cabinet Filter & Replace & Visual/By hand & & \\
\hline $\begin{array}{l}\text { Check for damage \& tight terminals of } \\
\text { breaker }\end{array}$ & Shouldn't loose & Visual/By hand & & \\
\hline Lubrication Tank & Check and Clean & Visual/By hand & & \\
\hline ATC Position & $\begin{array}{l}\text { ATC Arm fixed and Z-axis home } \\
\text { position }\end{array}$ & Visual/By hand & & \\
\hline Slide Cover Condition & $\mathrm{X}, \mathrm{Y} \& \mathrm{Z}$ axis & Visual/By hand & & \\
\hline Main electrical Panel & Clean from dust & Visual/By hand & & \\
\hline Replace 4th Axis unit oil & Replace if require & Visual/By hand & & \\
\hline
\end{tabular}

[12] [13]. 


\section{Results}

The results from implemented sheets shows that above sheet overcomes most of the issues and a significant improvements have been done after implementation of sheet especially for daily check points. Over the years, Maintenance and its cost continue, unplanned failures decrease the reliability of the machine and also it costs amount for maintenance. Above implemented sheets can be a significant drop in costs. Proper maintenance of machine can save money and time factor specially cost of technical support for serious problems from manufacturers.

Results are concluded on the basis of three completion of schedule periods after implementation of PM sheet on 20 CNC units. A successful reduction of more than 80 percent been calculated for most check points after comparing with the breakdowns before implementation of sheet.

\section{Conclusion}

In this study, about CNC machine, I proposed a Preventive maintenance approach, which is used to find out time between preventive maintenance of different parts of $\mathrm{CNC}$ milling machine. The proposed PM methodology finally results that the preventive maintenance concerning to the operation of CNC Milling machine should be carried out according to the time as per given the sheet, which can help to increase the life of the tool and machine without any failure or breakdown occurring. Also it saves the time wasted because of breakdowns in units, which shows its reliability for continuous industrial processes. Although, PM sheet for CNC milling machines, which defines check point detail, standard for checking and check methods in such detail never developed before.

\section{Acknowledgements}

The work was done to improve the quality of production units (CNC's) in Atlas Honda, Pakistan as a part of my project. I would like to give my gratitude to my supervisor Mr. Naveed Ahmad (H. O. D of maintenance department), who provided me opportunity to work on this project. I would like to thank all the other members from Atlas Honda, for their cooperation to improve my research work on $\mathrm{CNC}$ Milling machines.

\section{References}

[1] Dhillon, B. S., Maintainability, maintenance, and reliability for engineers. 2006: CRC Press.

[2] VenkataramanV. Maintenance engineering and management. PHI Learning Private Limited 2010.

[3] Ashayeri, J., Development of computer-aided maintenance resources planning (CAMRP): A case of multiple $\mathrm{CNC}$ machining centers. Robotics and Computer-Integrated Manufacturing, 2007. 23 (6): p. 614-623.

[4] Marseguerra M, Zio E, Podofillini L. Condition-based maintenance optimization by means of genetic algorithms and Monte Carlo simulation [J]. Reliability Engineering \& System Safety, 2002, 77 (2): 151-165.

[5] Mazzuchi TA, Soyer R. Assessment of Machine Tool Reliability Using a Proportional Hazards Model [J], Naval Research Logistics, 1989 (13): 405-424.

[6] "Srivastava, Mayank. (2013).”.

[7] Amilla, Venkata. (2016). Study on computer numerical control $(\mathrm{CNC})$ machines. International Journal of Advanced Scientific Research.

[8] SRIDHAR, NITISH, and RAHUL SELVAM. "Research study on Dynamism of Checklist in Preventive Maintenance".

[9] FIIX, 15 November, 2017. [Online]. Available: https://www.fiixsoftware.com/blog/3-causes-of-equipmentfailure-and-what-you-can-do-to-prevent-it/.

[10] I. P. S., A. and K. J. S., Total productive maintenance: literature review and directions. International Journal of Quality \& Reliability Management, 2008. 25 (7): p. 709-756.

[11] Swanson, L., Linking maintenance strategies to performance. International journal of production economics, 2001. 70(3): $p$. 237-244.

[12] Okuma, 2017 November, 06. [Online]. Available: https://www.okuma.com/handy-checklist-for-preventivemaintenance.

[13] "Cerebral Meltdown," 2017 November, 06. [Online]. Available: https://www.cerebralmeltdown.com/cncstuff/page2/checklist/i ndex.htm. 